\title{
Inhibition of Transient Receptor Potential Melastain 7 Enhances Apoptosis Induced by TRAIL in PC-3 cells
}

\author{
Chang-Ming Lin ${ }^{1,2}$, Ji-Min Ma ${ }^{3}$, Li Zhang ${ }^{1,4}$, Zong-Yao Hao ${ }^{1}$, Jun Zhou ${ }^{1}$, Zhen- \\ Yu Zhou ${ }^{5}$, Hao-Qiang Shi ${ }^{1}$, Yi-Fei Zhang ${ }^{1}$, En-Ming Shao ${ }^{6}$, Chao-Zhao Liang ${ }^{1 *}$
}

\begin{abstract}
Transient receptor potential melastain 7 (TRPM7) is a bifunctional protein with dual structure of both ion channel and protein kinase, participating in a wide variety of diseases including cancer. Recent researches have reported the mechanism of TRPM7 in human cancers. However, the correlation between TRPM7 and prostate cancer (PCa) has not been well studied. The objective of this study was to investigate the potential the role of TRPM7 in the apoptosis of PC-3 cells, which is the key cell of advanced metastatic PCa. In this study, we demonstrated the influence and potential function of TRPM7 on the PC-3 cells apoptosis induced by TNF-related apoptosis inducing-ligand (TRAIL). The study also found a novel up-regulated expression of TRPM7 in PC-3 cells after treating with TRAIL. Suppression of TRPM7 by TRPM7 non-specific inhibitors $\left(\mathrm{Gd}^{3+}\right.$ or 2-aminoethoxy diphenylborate (2-APB) ) not only markedly eliminated TRPM7 expression level, but also increased the apoptosis of TRAIL-treated PC-3 cells, which may be regulated by the phosphatidylinositol 3-kinase/protein kinase B (PI3K/AKT) signaling pathway accompany with up-regulated expression of cleaved Caspase-3, (TRAIL-receptor 1, death receptors 4) DR4, and (TRAIL-receptor 2, death receptors 5) DR5. Taken together, our findings strongly suggested that TRPM7 was involved in the apoptosis of PC-3 cells induced by TRAIL, indicating that TRPM7 may be applied as a therapeutic target for PCa.
\end{abstract}

Keywords: Transient receptor potential melastain 7 (TRPM7)- Prostate Cancer (PCa)-PC-3 cells-TNF-related apoptosis inducing-ligand (TRAIL) Apoptosis-TRPM7 inhibitors

Asian Pac J Cancer Prev, 16 (10), 4469-4475

\section{Introduction}

Prostate cancer $(\mathrm{PCa})$ is the commonest malignancy among men worldwide. In 2013, the United States (US) has estimated that there were nearly 238,590 diagnosed PCa and rank it is the first ratio about $28 \%$ in new cancer cases of men(Siegel et al., 2013). The recurrence of disease after primary treatment or at the advanced stage, the patients have to receive androgen deprivation therapy, but the disease still head to Castration-resistant prostate cancer (CRPC) present with metastasis after 1824 months (Jemal et al., 2008). PC-3 cells were initiated from a bone metastasis of a grade IV prostate cancer and they were primary cells for patient at the stage of CRPC which leads to significant patient mortality (Tannock et al., 2004). Currently, it is well established that improving live quality and prolonging survival time of $\mathrm{PCa}$ are focused on mechanism of signal pathway in PC-3 cells, especially for the phosphatidylinositol 3-kinase/protein kinase B (PI3K/AKT) signaling pathway. Notably, Sahni reported that TRPM7 is required for PI3K/AKT-dependent growth signaling as a central regulator of lymphocyte growth and proliferation (Sahni and Scharenberg, 2008).

TRPM7, a member of the largest and most diverse TRPM subfamily (TRPM1-8) of TRP superfamily, is nonselective cation channel (Gaudet, 2008). TRPM7 is well accepted as important regulators of $\mathrm{Mg}^{2+}$ homeostasis and transportor of other cations (Runnels et al., 2001; Ryazanova et al., 2010). Structurally, it is similar to other TRPs which have six transmembrane domains with a hydrophobic central pore or channel and the amino- and carboxyl-terminals ( $\mathrm{N}$ - and $\mathrm{C}$-terminals) facing the intracellular side of the membrane by flank of transmembrane segments (Latorre et al., 2009). Nowadays, TRPM7 has became a highlight in cancer researches.

Though other TRP channels (TRPM8 and TRPV6) have been identified in the human prostate physiology or carcinogenesis (Van Haute et al., 2010), the research of TRPM7 in PCa is rare and potential functions of TRPM7

${ }^{I}$ Department of Urology, The First Affiliated Hospital of Anhui Medical University, Hefei, ${ }^{2}$ The Central Hospital of Maanshan The Affiliated Hospital of Wannan Medical College, Maanshan, ${ }^{6}$ The Municipal people`s hospital of Maanshan, Anhui, ${ }^{5}$ The First people`s hospital of Suqian, Jiangsu, ${ }^{3}$ Emergency medical center, The Central Hospital of Maanshan The Affiliated Hospital of Wannan Medical College, Maanshan, ${ }^{4}$ Institute of Urology, Anhui Medical University, Hefei, Anhui, China *For correspondence: liang_chaozhao@163.com 
Chang-ming Lin et al

in the survival of PC-3 cells are still unknown. Thus, we examined the expression of TRPM7 in PC-3 cells in this study. Our data suggested that TRPM7 play an important role in the survival of PC- 3 cells. In addition, one other molecule to note is the TRAIL, a member of TNF super family, is expressed in various human fetal and adult tissues including the spleen, prostate, small intestine, and placenta (Wiley et al., 1995). Notably, it selectively induces apoptosis in cancer cells but not or low cytotoxicity to normal cells (Nieminen et al., 2007). TRAIL-based therapies demonstrate selective antitumor ability in PCa and other cancers (Koschny et al., 2007). Therefore, TRAIL is considered as a promising therapeutic agent for PCa (Wang et al., 2013). As a result, we demonstrated that TRPM7 has potential correlation with PC-3 cells apoptosis induced by TRAIL. This effect was mediated, at least in part, by the PI3K signaling pathways. Therefore, it is possible that TRPM7 maybe a novel target for the treatment of PCa in the near future.

\section{Materials and Methods}

\section{Cell culture}

The PC-3 cells were obtained from Chinese Academy of Sciences, Shanghai, China. The cell line was maintained in Dulbecco's modified Eagle's medium (DMEM) (Gibco, MD, USA) supplemented with $10 \%$ fetal bovine serum(FBS), $100 \mathrm{U} / \mathrm{mL}$ penicillin and 100 $\mathrm{mg} / \mathrm{mL}$ streptomycin at $37^{\circ} \mathrm{C}$ with $5 \% \mathrm{CO}_{2}$ humidified atmosphere and passaged as needed. The growth medium was renewed every 2 days.

\section{Treat PC-3 cells with TRAIL, Gd $d^{3+}$ and 2-APB}

Based on experimental procedure, after that, cells were pretreated with $25 \mathrm{ng} / \mathrm{ml}$ TRAIL (Peprotech, Rocky Hill, USA) for $48 \mathrm{~h}$ followed by the treatment with $\mathrm{Gd}^{3+}$ $50 \mu \mathrm{mol} / \mathrm{L}$ (Sigma, US) or 2-APB $100 \mu \mathrm{mol} / \mathrm{L}$ (Sigma, USA) for $24 \mathrm{~h}$. 和 The number of cells used in the experiments was $1 \times 10^{5}$.

\section{RNA interference analysis}

Small interfering RNA (siRNA) sequences against TRPM7 genes and scrambled siRNA sequences were synthesized by the Gena Pharma Corporation (Shanghai, China). The sequences as follows: TRPM7 siRNA(human) 5'-CCACUGGACUUACGAAUAUTT-3' for the sense strand and 5'-AUAUUCGUAAGUCCAGUGGTT-3' for the antisense strand. PC-3 cells $\left(1 \times 10^{5}\right.$ cells $)$ were cultured in 6-well plates with OPTI-DMEM for $24 \mathrm{~h}$ and then subjected to transfection with siRNA using Lipofectamine ${ }^{\mathrm{TM}} 2000$ (Invitrogen, CA, USA) according to the manufacturer's protocol. Knockdown efficiency was determined by RT-PCR and Western blot analysis. All experiments were repeated at least three times.

\section{MTT assay}

MTT (3-‘4,5-dimethylthiazol-2-yl' - 2,5diphenyltetrazolium bromide) assay was used to assess cell viability. PC-3 cells were seeded into each well of 96-well culture plates and then cultured in DMEM supplemented with other reagents for $24 \mathrm{~h}$. After incubation, $100 \mu \mathrm{l}$ of MTT solution $(5 \mathrm{mg} / \mathrm{mL})$ was added to each well, and the plates were then incubated at $37^{\circ} \mathrm{C}$ for $4 \mathrm{~h}$. After removing the supernatant and shaking with $200 \mu \mathrm{L}$ of Dimethyl Sulfoxide (DMSO) (Sigma, CA, USA) for 30 min, absorbance was measured at $490 \mathrm{~nm}$. All experiments were repeated at least three times.

\section{Semi-quantitative reverse transcription-polymerase chain reaction $(R T-P C R)$}

Isolation of total RNA was done with RNeasy Mini kit (Qiagen, Dusseldorf, Germany). First-strand DNA was generated from $0.5 \mu \mathrm{g}$ of total RNA using oligo (dT) and reverse transcriptase SuperScript II (Invitrogen, CA, USA) at a reaction volume of $20 \mu \mathrm{L}$. An oligo nucleotide primer pair was synthesized over regions specific for rat TRPM7 cDNA. A primer pair for the detection of human $\beta$-actin was used as the internal control. Negative control in PCR reaction was done by replacing cDNA with ultrapure water. PCR primers are as follows in Table 1. Reverse transcription products were PCR-amplified with 35 cycles of $40 \mathrm{sec}$ at $95^{\circ} \mathrm{C}, 40 \mathrm{sec}$ at $54^{\circ} \mathrm{C}$, and $1 \mathrm{~min}$ at $72^{\circ} \mathrm{C}$ using ABI9700 (Applied Biosystems, CA, USA). The amplified cDNA was run on $1 \%$ agarose gels and visualized under UV light following staining. The band intensities of amplification products were measured by a densitometer, and the results were normalized with $\beta$-actin. The results were repeated at least three times independently from three different pools of templates, while each pool of template was extracted from at least eight ventricles.

\section{Western blot analysis}

PC-3 cells were lysed with RIPA lysis buffer (Beyotime, Hangzhou, China). Whole extracts were prepared, and protein concentrations were measured using a BCA protein assay kit (Boster, Wuhan, China). Total proteins (30 or $50 \mathrm{mg}$ ) were separated by SDS-PAGE and blotted onto PVDF membranes (Millipore, MA, USA). After the blockade of nonspecific protein binding with $5 \%$ milk, nitrocellulose blots were incubated for $6 \mathrm{~h}$ with primary antibodies diluted in Dilution Buffer (Beyotime, Hangzhou, China). Rabbit polyclonal antibody recognizing TRPM7 (Abcam, CA, UK) was used at 1:1500, rabbit polyclonal anti-(TRAIL-receptor 1 , death

Table 1. Primers Used for RT-PCR

\begin{tabular}{lll}
\hline Gene & \multicolumn{1}{c}{ Forward } & \multicolumn{1}{c}{ Reverse } \\
\hline TRPM7 & 5'-CCATACCATATTCTCCAAGGTTCC-3' & 5'-CATTCCTCTTCAGATCTGGAAGTT-3' \\
DR-4 & 5'-CAGAACGTCCTGGAGCCTGTAAC-3' & 5'-ATGTCCATTGCCTGATTCTTTGTG-3' \\
DR-5 & 5'-GGGAAGAAGATTCTCCTGAGATGTG-3' & 5'-ACATTGTCCTCAGCCCCAGGTCG-3' \\
$\beta$-actin & 5'-CCCACA CTGTGCCCATCTACG -3' & 5'-GCCATCTCTTGCTCGAAGTCC -3' \\
\hline
\end{tabular}


receptors 4) DR4 (Boster, Wuhan, China) was diluted at 1:600, human monoclonal antibody directed against (TRAIL-receptor 2, death receptors 5) DR5 (Abcam, CA, UK) was used at 1:1000, human monoclonal anti$\beta$-actin (Boster, Wuhan, China) was used at 1:500, rabbit monoclonal antibodies against AKT, and phospho-AKT (Cell Signaling, USA) were used at 1:1000, and human monoclonal antibody against $\beta$-actin (Santa Cruz, CA, USA) was used at 1:500.

Following incubation with primary antibodies, blots were washed three times in TBS/Tween-20 before incubation for $1 \mathrm{~h}$ in goat anti-mouse or goat antirabbit horseradish peroxidase (Santa Cruz, CA, USA) conjugate antibody at 1:10,000 dilution in TBS/Tween-20 containing 5\% skim milk. After extensive washing in TBS/Tween-20, blots were washed with distilled water and processed for antigen detection of antigen using the ECL-chemiluminescent kit (Thermo Scientific, MA, USA). $\beta$-actin was used as loading control. Experiments were repeated at least three times from three independent protein extracts.

\section{Flow cytometric analysis}

Media and cells from untreated and treated samples were collected by trypsinization, and washed twice with cold PBS buffer. After resuspended in $400 \mu \mathrm{L}$ Annexin-V binding buffer, cells were stained with $5 \mu \mathrm{L}$ Annexin-V FITC (BD Pharmingen, CA, USA) incubated at $2-8^{\circ} \mathrm{C}$ for $15 \mathrm{~min}$, then stained with $10 \mu \mathrm{l}$ propidium iodide (PI) incubated at $2-8^{\circ} \mathrm{C}$ for $5 \mathrm{~min}$ in dark before read on a BD LSR flow cytometer (BD Biosciences). Data was processed with Cell Quest Pro (BD Biosciences). All experiments were repeated at least three times.

\section{Statistical analysis}

Data are expressed as mean \pm SE. Student's t test and ANOVA were evaluated for the analysis of statistical significance. A p-value $<0.05$ of two sides was taken to consider statistically significant.

\section{Results}

\section{Effect of TRAIL on apoptosis of PC-3 cells}

Firstly, PC-3 cells were treated by TRAIL $(3.125,6.25$, $12.5,25$, and $50 \mathrm{ng} / \mathrm{ml})$. As shown in Figurere 1A, the viability of PC-3 cells was decreased by TRAIL (3.125, $6.25,12.5,25$, and $50 \mathrm{mg} / \mathrm{ml})$. Furthermore, we chose the concentration of $25 \mathrm{ng} / \mathrm{ml}$ for the following experiments. After PC-3 cells were cultivated with $25 \mathrm{ng} / \mathrm{ml}$ TRAIL for $48 \mathrm{~h}$, flow cytometric analysis demonstrated the apoptosis of PC-3 cells was significantly increased by the TRAIL 25 $\mathrm{ng} / \mathrm{ml}$ compared to normal group (Figurere 1B).

Effect of TRAIL on the expression of TRPM7 in PC-3 cells

PC-3 cells were cultivated with $25 \mathrm{ng} / \mathrm{ml}$ TRAIL for $48 \mathrm{~h}$. The expression of TRPM7 mRNA and protein were significantly up-regulated by the cultivation of TRAIL compared to normal group, as shown in Figure 1C, D.

Effect of TRPM7 inhibitors in PC-3 cells

$\mathrm{Gd}^{3+}$ and 2-APB, two non-specific TRPM7 channel inhibitors, were used to inhibit TRPM7 expression in PC- 3 cells. In addition, $\operatorname{Gd}^{3+}(12.5,25,50$ and $100 \mu \mathrm{mol} / \mathrm{l})$ or 2 -APB $(25,50,100$ and $200 \mu \mathrm{mol} / \mathrm{l})$ decreased the viability of PC-3 gradually with MTT assays (Figure 2A, B). Based on the above result, we chose $50 \mu \mathrm{mol} / 1$ of $\mathrm{Gd}^{3+}$ and $100 \mu \mathrm{mol} / 1$ of 2-APB for the following experiments. As shown in Figurere 2C, PC-3 cells were treated by TRPM7-siRNA $(0.1,0.2,0.4,0.8 \mu \mathrm{mol} / \mathrm{l})$, the expression

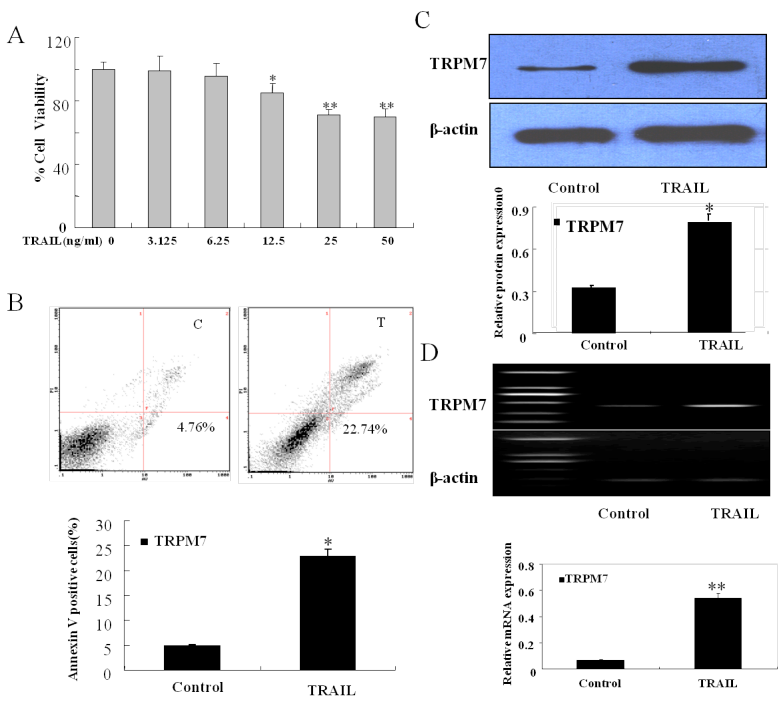

Figure 1. Effect of TRAIL on the TRPM7 Expression in PC-3 Cells. (A) Concentration-dependent inhibition of PC-3 cells apoptosis induced by TRAIL, which was tested by MTT assays. (B) Apoptosis of PC-3 cells was analyzed by flow cytometry with Annexin V-FITC and PI staining. Fluorescence intensity for Annexin V-FITC is plotted on the $\mathrm{x}$-axis, and PI is plotted on the y-axis. TRAIL $(25 \mathrm{ng} / \mathrm{ml})$ increased the apoptosis rate of activated PC-3 cells. (C and D) Molecular changes of TRPM7 mRNA and protein expression in PC-3 cells approximately $48 \mathrm{~h}$ after TRAIL $(25 \mathrm{ng} / \mathrm{ml})$ cultivation. C: Control, T: TRAIL

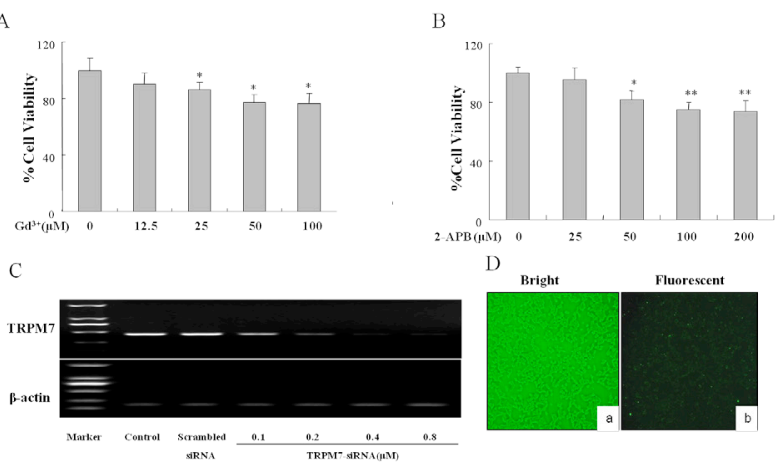

Figure 2. Effect of TRPM7 Inhibitors and TRPM7siRNA on Cell Viability in PC-3 cells. (A) Concentrationdependent inhibition of the cell proliferation of PC-3 cells by $\mathrm{Gd}^{3+}$, tested by MTT assays. (B) Concentration-dependent inhibition of the cell proliferation of PC-3 cells by 2-APB, tested by MTT assays. Results are the mean \pm SD from three independent experiments. ${ }^{*} \mathrm{P}<0.05$ and $* * \mathrm{P}<0.01$ vs control. (C) PC-3 cells were seeded in 6-well plates and transfected with TRPM7-siRNA for $48 \mathrm{~h}$. RT-PCR images analysis shows reduced expression of TRPM7 mRNA by TRPM7-siRNA. (D) PC-3 cells transfected with TRPM7-siRNA in ordinary white light (left) and green fluorescence (right) by fluorescence microscope $(\times 100)$ 
Chang-ming Lin et al

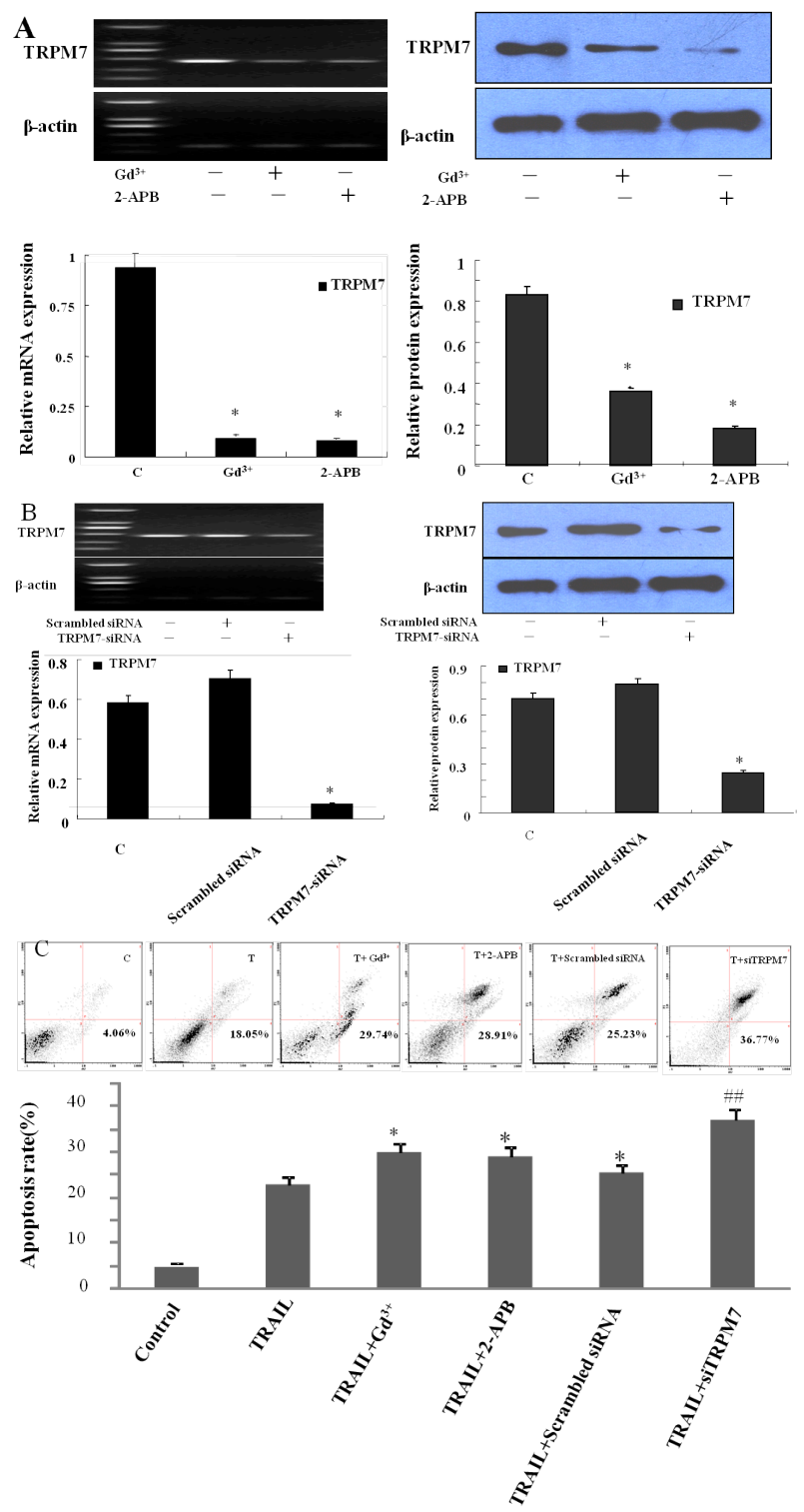

Figure 3. Molecular changes of TRPM7 expression in PC-3 cells. (A) $\mathrm{Gd}^{3+}(50 \mu \mathrm{mol} / \mathrm{L})$ or 2 -APB $(100 \mu \mathrm{mol} / \mathrm{L})$ inhibited the expression of TRPM7 mRNA and protein in PC-3 cells. (B) TRPM7-siRNA inhibited the expression of TRPM7 mRNA and protein in PC-3 cells. (C) Effect of TRPM7 sinlencing on the apoptosis of PC-3 cells, measured by flow cytometry with Annexin V-FITC and PI staining.. C: Control; T: TRAIL $(25 \mathrm{ng} / \mathrm{mL})$. Results are the mean \pm SD from three independent experiments. ${ }^{*} \mathrm{p}<0.05$ and ${ }^{*} * \mathrm{p}<0.01$ vs control; "p $<0.05$ and ${ }^{\# \prime} \mathrm{p}<0.01$ vs scrambled siRNA with TRAIL

of TRPM7 was significant suppressed at $0.4 \mu \mathrm{mol} / 1$, which was used for the following experiments.

\section{Effect of TRPM7 on PC-3 cells apoptosis induced by TRAIL}

Firstly, as we showed above, the apoptosis of PC-3 cells incubated with TRAIL were increased compared to normal group, while, addition of $50 \mu \mathrm{mol} / \mathrm{l} \mathrm{Gd}^{3+}$ or $100 \mu \mathrm{mol} / 12$ 2-APB with TRAIL, the apoptosis of PC-3 cells were significantly increased. Likewise the same result in TRPM7-siRNA group. This present study also confirmed that the expression of TRPM7 was decreased. As shown in Figurere 3A-B, TRPM7 inhibitors $\left(\mathrm{Gd}^{3+}\right.$ or
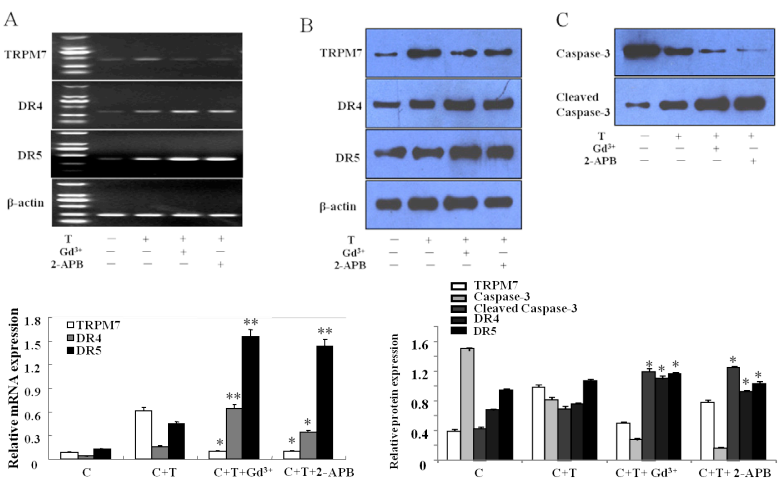

Figure 4. Effect of Reducing TRPM7 Expression on PC-3 Cells Apoptosis Induced by TRAIL. PC-3 Cells were added with $\mathrm{Gd}^{3+}(50 \mu \mathrm{mol} / \mathrm{L})$ or 2 -APB $(100 \mu \mathrm{mol} / \mathrm{L})$ for $48 \mathrm{~h}$. (A) RT-PCR images analysis shows reduced expression of TRPM7 mRNA by Gd ${ }^{3+}(50 \mu \mathrm{mol} / \mathrm{L})$ or 2 -APB $(100 \mu \mathrm{mol} / \mathrm{L})$. Meanwhile, RT-PCR analysis shows increased expression of DR4 and DR5 mRNA by $\mathrm{Gd}^{3+}(50 \mu \mathrm{mol} / \mathrm{L})$ or 2 -APB $(100$ $\mu \mathrm{mol} / \mathrm{L}$ ). (B) Western blot shows TRPM7 protein was inhibited by $\mathrm{Gd}^{3+}(50 \mu \mathrm{mol} / \mathrm{L})$ or 2 -APB $(100 \mu \mathrm{mol} / \mathrm{L})$. Meanwhile, the expression of DR4 and DR5 protein were increased by $\mathrm{Gd}^{3+}$ $(50 \mu \mathrm{mol} / \mathrm{L})$ or 2 -APB $(100 \mu \mathrm{mol} / \mathrm{L})$. (C) Western blot shows Caspase- 3 protein was inhibited by $\mathrm{Gd}^{3+}(50 \mu \mathrm{mol} / \mathrm{L})$ or 2 -APB $(100 \mu \mathrm{mol} / \mathrm{L})$ and cleaved Caspase-3 protein was induced by $\mathrm{Gd}^{3+}(50 \mu \mathrm{mol} / \mathrm{L})$ or 2 -APB $(100 \mu \mathrm{mol} / \mathrm{L})$. Results are the mean \pm SD from three independent experiments. ${ }^{p} p<0.05$ and $* * \mathrm{p}<0.01$ vs TRAIL
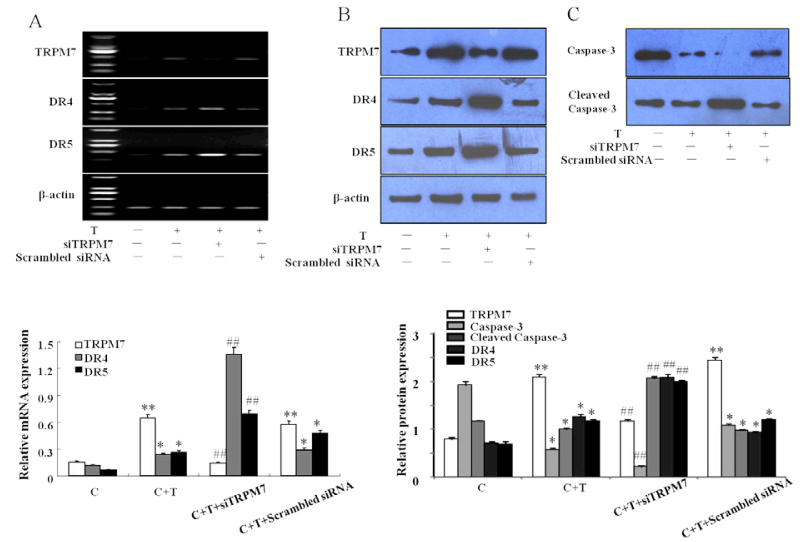

Figure 5. Effect of TRPM7-siRNA on PC-3 Cells Apoptosis Induced by TRAIL. Cells were transfected with TRPM7-siRNA or scrambled siRNA for $48 \mathrm{~h}$. TRAIL was applied to induce apoptosis. (A) RT-PCR analysis shows downregulated expression of TRPM7 mRNA by TRPM7siRNA. Meanwhile, RT-PCR images analysis shows increased expression of DR4 and DR5 mRNA by TRPM7-siRNA. (B) Western blot shows TRPM7 protein was inhibited by TRPM7siRNA. Meanwhile, the expression of DR4 and DR5 protein were increased by TRPM7-siRNA. (C) Western blot shows Caspase-3 protein was inhibited by TRPM7-siRNA. Cleaved Caspase- 3 protein was induced by TRPM7-siRNA. Results are the mean \pm SD from three independent experiments. $* \mathrm{p}<0.05$ and ${ }^{* *} \mathrm{p}<0.01$ vs control, ${ }^{\#} \mathrm{p}<0.05$ and ${ }^{\# \#} \mathrm{p}<0.01$ vs scrambled siRNA with TRAIL

2-APB) and TRPM7-siRNA could inhibit expression of TRPM7 in TRAIL-treated PC-3 cells. It is well known that Caspase- 3 activation is one of the hallmarks of apoptotic cell death. The result showed that the activated Caspase-3 was increased under the $\mathrm{PC}-3$ cells cultivation of $\mathrm{Gd}^{3+}$ or 

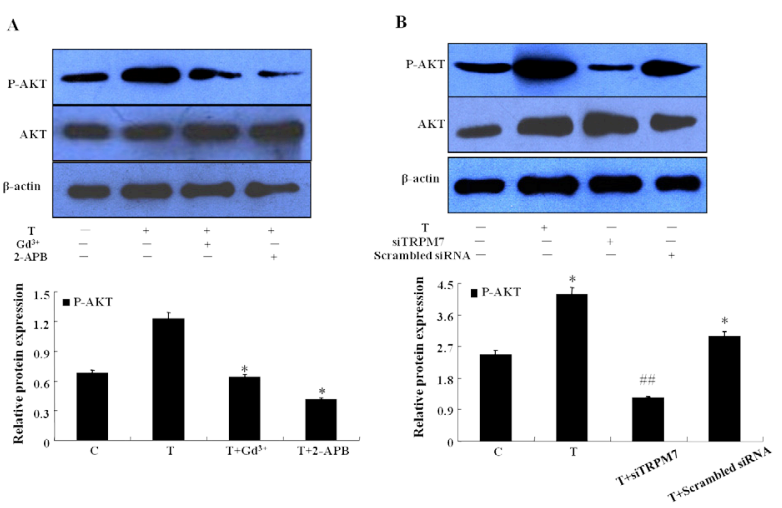

Figure 6. Effect of downregulated TRPM7 on the AKT phosphorylation in PC-3 cells. (A) Western blot images shows attenuated phosphorylation of Akt in PC-3 cells $48 \mathrm{~h}$ following treatment with $\mathrm{Gd}^{3+}$ or 2 -APB. ${ }^{*} \mathrm{p}<0.05$, $* * \mathrm{p}<0.01$ vs control. (B) Western blot images shows decreased TRPM7 and phosphorylation of AKT in PC-3 cells following the transfection of TRPM7-siRNA. Results are the mean \pm SD from three independent experiments. ${ }^{*} \mathrm{p}<0.05$ and $* * \mathrm{p}<0.01 v s$ control, ${ }^{\#} \mathrm{p}<0.05$ and $^{\# \#} \mathrm{p}<0.01$ vs scrambled siRNA with TRAIL
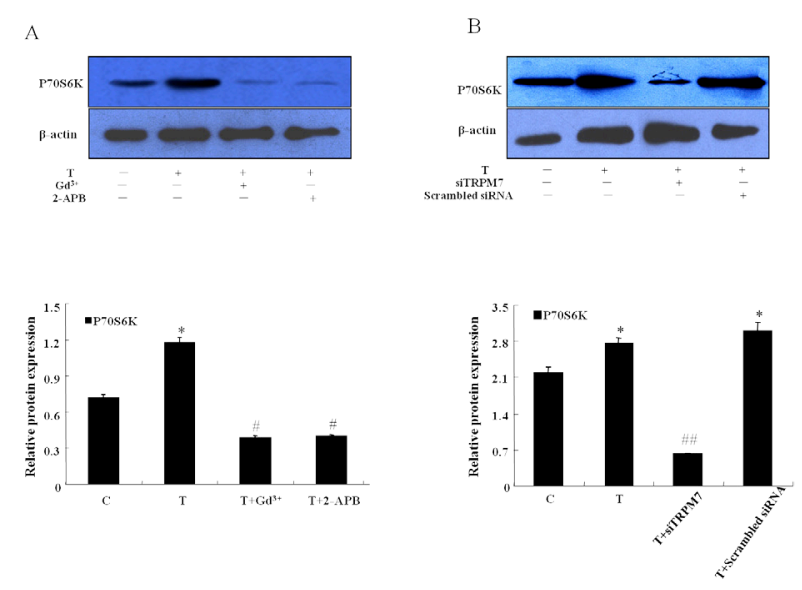

Figure 7. Effect of Downregulated TRPM7 on the P70S6K Protein Expression in PC-3 Cells. (A) PC-3 cells were treated by $\mathrm{Gd}^{3+}$ or 2 -APB for $48 \mathrm{~h}$ with or without TRAIL and whole-cell protein extracts were made. Western blot analyses of P70S6K protein were performed. Results are the mean \pm SD from three independent experiments. ${ }^{*} \mathrm{p}<0.05$ vs control, ${ }^{\#} \mathrm{p}<0.05$ vs TRAIL. (B) PC-3 cells transfected with TRPM7-siRNA or scrambled-siRNA were harvested $48 \mathrm{~h}$ after transfection and whole-cell protein extracts were made. Western blot analyses of P70S6K protein were performed. Results are the mean \pm SD from three independent experiments. $* \mathrm{p}<0.05$ vs control, ${ }^{\# \#} \mathrm{p}<0.01$ vs Scrambled siRNA. C: Control, T: TRAIL

2-APB with TRAIL, the same tendency were identified in DR4 or DR5 which TRAIL binding result in apoptosis (Figurere. 4). Moreover, TRPM7-siRNA could increase the apoptosis of PC-3 cells induced by TRAIL compared to control. Meantime, the TRPM7 expression was decreased, accompany with upregulated expressions of activated Caspase-3, DR4, and DR5 (Figurere. 5). Taken together, all the above data demonstrated that blocking TRPM7 could enhance the apoptosis of PC-3 cells induced by TRAIL. Therefore, TRPM7 play an important role in the survival of PC-3 cells.

\section{Effect of TRPM7on the activation of AKT pathways}

Previous studies have confirmed that PC- 3 cells could grow largely via PI3K/AKT signaling pathways (Lescarbeau and Kaplan, 2014). Therefore, the PI3K/AKT signaling pathway was evaluated in this study to detect whether it was affected by TRPM7. The study showed that the expression of p-AKT was increased in PC-3 cells induced by TRAIL, whereas the expressions of total AKT proteins remained unchanged (Figure 6A). Furthermore, treatment with $\mathrm{Gd}^{3+}$ or 2-APB diminished TRAILmediated up-regulation of p-AKT in PC-3 cells (Figurere. 6A). Ultimately, we determined if TRPM7 silencing affects the activity of AKT by analyzing the expression of p-AKT in PC-3 cells. The result in figure. 6B showed a decrease in p-AKT in TRAIL-treated PC-3 cells transfected with TRPM7-siRNA in comparison to the Scrambled-siRNA group. P70S6K, a downstream effector of the PI3K/AKT pathway, has been shown to regulate proliferation and cell survival in PC-3 cells (Saraswati et al., 2013). Thus, we investigated the effect of TRPM7 on P70S6K activation by assessing its phosphorylation status in PC-3 cells. P70S6K phosphorylation was induced by TRAIL (Figure. 7A and B). In contrast, PC- 3 cells cultured with TRAIL and $\mathrm{Gd}^{3+}$ or 2-APB showed a down-regulated phosphorylation of P70S6K (Figure 7A). Transfection of TRPM7-siRNA in TRAIL-stimulated PC-3 cells decreased phosphorylation of P70S6K compared to Scrambled-siRNA group (Figure 7B). These results suggested that the blockade of TRPM7 decrease the phosphorylation level of AKT in PC-3 cells.

\section{Discussion}

Up to date, PCa remains the second leading cause of death among men, with estimated 29,480 deaths from their diseases in the USA in 2014 (Siegel et al., 2014). The symptom of the disease varies from indolent to highly aggressive cancer that metastasizes and even result in death. Because of the heterogeneity of $\mathrm{PCa}$, exploring disease-specific molecular mechanisms is a rational approach.

Recent researches demonstrated that TRP channels are involved in all basic cellular processes, such as maintaining tissue homeostasis via proliferation, differentiation, and apoptosis (Lehen'kyi et al., 2011). Nowadays, some TRP channels have been crucial for cancer development and growth (Kunzelmann, 2005). Of all the TRP channels, TRPM7 has been caught attention by scientist due to its unique structure of possessing a ion channel and a kinase domain. It can permeate divalent and monovalent cations as a result of the ion channels characteristis (Runnels et al., 2001; Ryazanova et al., 2010). TRPM7 was expressed widely in the body including heart, liver, kidney, lung, and brain (Minke and Cook, 2002; Montell et al., 2002; Montell, 2005; Abed and Moreau, 2007). Moreover, it can participate in a number of physiological and pathophysiological processes that involve in excitability, gene expression, muscle contraction, cell volume regulation, and hormone secretion (Bodding, 2007; Jin et al., 2008). More and more studies confirmed that TRPM7 play a vital role in cancer. For example, TRPM7 has become a proliferative marker 
of poorly differentiated breast cancer. It can also be used as a promising novel biomarker and a potential therapeutic target in the treatment of human estrogen receptor (-) invasive ductal carcinoma (IDC) (Ouadid-Ahidouch et al., 2012; Guilbert et al., 2013). However, the effect of TRPM7 on PCa is largely unknown. In the current study, the inhibitory effects and underlying molecular mechanisms of TRPM7 in PC-3 cells apoptosis were explored.

A series of studies have confirmed that the apoptosis of PC-3 cells can be induced by TRAIL. TRAIL is a promising anticancer agent, which can induce apoptosis in a wide range of cancers cells (Stuckey and Shah, 2013). As a therapeutic target, TRAIL has been extended to PCa and induce various degrees of apoptosis among different $\mathrm{PCa}$ cell lines including PC-3 cells (Munshi et al., 2001). Our results showed that TRPM7 was up-regulated in TRAILtreated PC-3 cells compared with control (Figurere 1C). As the TRPM7 inhibitor (Yu et al., 2013), $\mathrm{Gd}^{3+}$ or 2-APB decreased the mRNA and protein expression of TRPM7 in our study in reality (Figure 3A and B). Our data suggest that $\mathrm{Gd}^{3+}$ or 2-APB can increase the apoptosis of PC-3 cells induced by TRAIL (Figurere 3C). Next, we found that TRPM7-siRNA can also enhance the apoptosis of PC-3 cells induced by TRAIL (Figure 3C). It is generally known that TRAIL induces apoptosis in cancer cells by engaging the pro-apoptotic death receptors (DR4, DR5) and forming death inducing signaling complex (DISC) (Bucur et al., 2006). At the DISC, Caspase-3 was actived (cleaved Caspase-3) and promoted TRAIL binds with the receptor (Holoch and Griffith, 2009), leading to trigger the programmed cell death pathway (Allen and El-Deiry, 2012). Our study also demonstrated that TRPM7-siRNA can increase the expression levels of DR4, DR5, and cleaved Caspase- 3 dependently, which may provide potential targets for clinical PCa treatment (Figure 5). The similar result can be found in $\mathrm{Gd}^{3+}$ or 2-APB group (Figure 4).

Furthermore, mechanism of TRPM7 regulate function was discussed in this study. The PI3K/AKT signaling pathway has been implicated in the control of an extensive range of cellular activities, such as survival, proliferation. Recently, a study suggested that the pan-inhibitor of PI3K/AKT LY294002 was able to abrogate the TRAILinduced increase in cell proliferation (Fang et al., 2013). In addition, PI3K/Akt inhibitor AZD5363 failed to induce significant apoptosis in PC-3 cells. Our results indicated that the induction of AKT phosphorylation was increased by TRAIL, and the effect was inhibited by the TRPM7 inhibitor and TRPM7-siRNA (Figure 6). Moreover, P70S6K, the downstream effector of the PI3K/AKT pathway, was activated by TRAIL and then suppressed by TRPM7 inhibitor $\left(\mathrm{Gd}^{3+}\right.$ and 2-APB) or TRPM7-siRNA (Figure7). A novel study indicated that TRPM7 regulates cell proliferation through a requirement of its channel function for sustained activation of PI3K pathways(Sahni and Scharenberg, 2008). In the present study, our data significantly suggested that $\mathrm{Gd}^{3+}, 2-\mathrm{APB}$, or TRPM7 silencing dramatically decreased the phosphorylation of AKT. Therefore, we believe that TRPM7 may negatively regulate PC-3 cells apoptosis partially by AKT signal pathways. During the activation of PC-3 cells, a series of alterations take place, which may affect the expression of TRPM7 and aggravate PCa. We identified a new mechanism for TRPM7 in recovery from PCa and provided new evidence for the use of TRPM7 inhibitors in antitumor therapy.

To our knowledge, this research into the genetic and pharmacologic function of TRPM7 may be the first report of a mechanism of PCa activation. In conclusion, we provide strong evidence that human PCa cells express functional TRPM7 channels that may play a vital role in modulating cell proliferation and differentiation, probably involved in the PI3K/Akt pathway. Therefore, inhibition of TRPM7 channels may prove to be a novel therapeutic approach for $\mathrm{PCa}$.

In conclusion, the anti-apoptosis effects and the possible mechanisms of TRPM7 were demonstrated in PC-3 cells. The present study demonstrated the role of TRPM7 in PCa and TRPM7 inhibitors could enhance the apoptosis of PC-3 cells induced by TRAIL might be mediated by the inhibition of PI3K/AKT activity. Based on it, therapies directed at combining TRPM7 inhibitors with TRAIL, specifically in PC-3 cells, may be useful to treat $\mathrm{PCa}$.

\section{Acknowledgements}

This study is supported by the National Natural Science Foundation of China (81170698,81370856,81470986), Clinical Key Subjects Program of the Ministry of Public Health of China (Urology), and Doctor Program Foundation of Ministry of Education of the China (No. 20113420110003).

\section{References}

Abed E, Moreau R (2007). Importance of melastatin-like transient receptor potential 7 and cations (magnesium, calcium) in human osteoblast-like cell proliferation. Cell Prolif, 40, 849-65.

Allen JE, El-Deiry WS (2012). Regulation of the human TRAIL gene. Cancer Biol Ther, 13, 1143-51.

Bodding M (2007). TRP proteins and cancer. Cell Signal, 19, 617-24.

Bucur O, Ray S, Bucur MC, et al (2006). APO2 ligand/tumor necrosis factor-related apoptosis-inducing ligand in prostate cancer therapy. Front Biosci, 11, 1549-68.

Fang L, Zhan S, Huang C, et al (2013). TRPM7 channel regulates PDGF-BB-induced proliferation of hepatic stellate cells via PI3K and ERK pathways. Toxicol Appl Pharmacol, 272, 713-25.

Gaudet R (2008). A primer on ankyrin repeat function in TRP channels and beyond. Mol Biosyst, 4, 372-9.

Guilbert A, Gautier M, Dhennin-Duthille I, et al (2013). Transient receptor potential melastatin 7 is involved in oestrogen receptor-negative metastatic breast cancer cells migration through its kinase domain. Eur J Cancer, 49, 3694-707.

Holoch PA, Griffith TS (2009). TNF-related apoptosis-inducing ligand (TRAIL): a new path to anti-cancer therapies. Eur J Pharmacol, 625, 63-72.

Jemal A, Siegel R, Ward E, et al (2008). Cancer statistics, 2008. CA Cancer J Clin, 58, 71-96.

Jin J, Desai BN, Navarro B, et al (2008). Deletion of Trpm7 disrupts embryonic development and thymopoiesis without 
altering $\mathrm{Mg}^{2+}$ homeostasis. Science, 322, 756-60.

Koschny R, Walczak H, Ganten TM (2007). The promise of TRAIL--potential and risks of a novel anticancer therapy. J Mol Med (Berl), 85, 923-35.

Kunzelmann K (2005). Ion channels and cancer. J Membr Biol, 205, 159-73.

Latorre R, Zaelzer C, Brauchi S (2009). Structure-functional intimacies of transient receptor potential channels. $Q$ Rev Biophys, 42, 201-46.

Lehen'kyi V, Shapovalov G, Skryma R, et al (2011). Ion channnels and transporters in cancer. 5. Ion channels in control of cancer and cell apoptosis. Am J Physiol Cell Physiol, 301, 1281-9.

Lescarbeau RM, Kaplan DL (2014). Quantitative analysis of castration resistant prostate cancer progression through phosphoproteome signaling. BMC Cancer, 14, 325.

Minke B, Cook B (2002). TRP channel proteins and signal transduction. Physiol Rev, 82, 429-72.

Montell C (2005). The TRP superfamily of cation channels. Sci STKE, 2005, 3.

Montell C, Birnbaumer L, Flockerzi V (2002). The TRP channels, a remarkably functional family. Cell, 108, 595-8.

Munshi A, Pappas G, Honda T, et al (2001). TRAIL (APO-2L) induces apoptosis in human prostate cancer cells that is inhibitable by Bcl-2. Oncogene, 20,3757-65.

Nieminen AI, Partanen JI, Hau A, et al (2007). c-Myc primed mitochondria determine cellular sensitivity to TRAILinduced apoptosis. EMBO J, 26, 1055-67.

Ouadid-Ahidouch H, Dhennin-Duthille I, Gautier M, et al (2012). [TRP calcium channel and breast cancer: expression, role and correlation with clinical parameters]. Bull Cancer, 99, 655-64.

Runnels LW, Yue L, Clapham DE (2001). TRP-PLIK, a bifunctional protein with kinase and ion channel activities. Science, 291, 1043-7.

Ryazanova LV, Rondon LJ, Zierler S, et al (2010). TRPM7 is essential for $\mathrm{Mg}^{(2+)}$ homeostasis in mammals. Nat Commun, 1, 109.

Sahni J, Scharenberg AM (2008). TRPM7 ion channels are required for sustained phosphoinositide 3-kinase signaling in lymphocytes. Cell Metab, 8, 84-93.

Saraswati S, Kumar S, Alhaider AA (2013). alpha-santalol inhibits the angiogenesis and growth of human prostate tumor growth by targeting vascular endothelial growth factor receptor 2-mediated AKT/mTOR/P70S6K signaling pathway. Mol Cancer, 12, 147.

Siegel R, Ma J, Zou Z, et al (2014). Cancer statistics, 2014. CA Cancer J Clin, 64, 9-29.

Siegel R, Naishadham D, Jemal A (2013). Cancer statistics, 2013. CA Cancer J Clin, 63, 11-30.

Stuckey DW, Shah K (2013). TRAIL on trial: preclinical advances in cancer therapy. Trends Mol Med, 19, 685-94.

Tannock IF, de Wit R, Berry WR, et al (2004). Docetaxel plus prednisone or mitoxantrone plus prednisone for advanced prostate cancer. $N$ Engl J Med, 351, 1502-12.

Van Haute C, De Ridder D, Nilius B (2010). TRP channels in human prostate. Scientific WorldJournal, 10, 1597-611.

Wang D, Lu J, Tindall DJ (2013). Androgens regulate TRAILinduced cell death in prostate cancer cells via multiple mechanisms. Cancer Lett, 335, 136-44.

Wiley SR, Schooley K, Smolak PJ, et al (1995). Identification and characterization of a new member of the TNF family that induces apoptosis. Immunity, 3, 673-82.

Yu M, Huang C, Huang Y, et al (2013). Inhibition of TRPM7 channels prevents proliferation and differentiation of human lung fibroblasts. Inflamm Res, 62, 961-70. 